\title{
¿Ha muerto la Reforma? La acción del movimiento estudiantil porteño durante la larga década de 1966 a 1976
}

\author{
Pablo Bonavena, Juan S. Califa y Mariano Millán \\ UBA - UNLP; UBA - Conicet; UBA - Conicet \\ bonavenapablo@yahoo.com.ar; jscalifa@hotmail.com; marianomillan82@gmail.com
}

\section{Introducción}

En nuestro país, entre el golpe de Estado de 1966, comandado por el general Juan Carlos Onganía, y la última dictadura iniciada en 1976 con la presidencia de Jorge Rafael Videla, se produjo un ascenso de masas. El movimiento estudiantil jugó allí un papel gravitante, ya sea por la cantidad y calidad de sus acciones, como por su capacidad para componer alianzas con el movimiento obrero en condiciones de enfrentamiento, especialmente en las acciones donde el sector sindical actuaba con autonomía de las tutelas burguesas.

Las hipótesis de uso común en la literatura académica sobre la radicalización estudiantil del período fueron construidas a partir del análisis del discurso de ciertas agrupaciones y referentes intelectuales, sin realizar una observación metódica de los actores, los escenarios y las acciones desarrolladas. Por esas y otras razones, desde distintos ángulos se ha afirmado que entre los años 60 y los 70 el reformismo universitario surgido en 1918, como ideario político y organizativo, entró en decadencia hasta prácticamente desaparecer frente al ascenso de la "nueva izquierda" y un nuevo "peronismo", en ocasiones considerados en estrecha relación (Gillespie, 1987: 96; Sigal, 1991: 71; Romero, 1994: 247 y ss.; James, 1999: 314 y ss.; De Riz, 2000: 95 y ss.; Tortti, 2000: 149; Barletta, 2001; Sarlo, 2001: 85 y ss.; Suasnábar, 2004: 82 y ss.). Tales argumentos, por cierto, no resultan exclusivos del mundo académico posterior a los acontecimientos, pues varios agrupamientos estudiantiles de la época sostenían explicaciones similares.

Estos presupuestos condujeron a afirmar que durante 1973, junto a la recuperación democrática, se produjo un ascenso universitario peronista resultante de una larga acumulación bajo la "Revolución Argentina” (Friedemann, 2015: 133 y ss.; Ghilini y Dipp, 2015). En tal

(Archivos, año VI, $\mathrm{n}^{\circ}$ 12, marzo de 2018, pp. 73-95) 
sentido, se considera que el escenario politico abierto durante la "primavera camporista” potenció la movilización precedente.

El presente escrito se ubica en una línea interpretativa opuesta por el vértice, en buena medida porque partimos de otra estrategia teórico-metodológica, que otorga centralidad a los enfrentamientos en la explicación de los procesos sociales, incluyendo la dimensión discursiva. Por ello, presentamos aquí una detallada contabilidad de las acciones protagonizadas por los alumnos de la UBA, quienes realizaron al menos 2.549 acciones de lucha que van desde comunicados hasta enfrentamientos con la policia, pasando por asambleas, actos, huelgas y demás. Nuestro objetivo principal consiste en presentar un examen sintético de la trayectoria del movimiento estudiantil, tomando como unidad de análisis los enfrentamientos sociales encarados por estudiantes que actuaron a partir de diversas identidades y grados de agregación. Para ello trabajamos con una base de datos construida con más de veinte diarios de circulación nacional y local (en el caso de Buenos Aires, La Nación, Clarín, La Opinión, La Prensa, Noticias, El Mundo, Mayoría, Crónica, edición matutina y vespertina, El Cronista Comercial y La Razón). ${ }^{1}$ A partir de la misma, clasificamos los hechos en diez variables de intervalo, seis con sistemas de categorias excluyentes (lugar, fecha, tipo de acción, escenario de la acción, cantidad de participantes y facultad donde ocurrió el hecho); y cuatro con categorías no excluyentes (protagonista/s, reclamo/s, aliado/s y enemigo/s).

Observaremos la evolución de las modalidades de lucha, de las organizaciones que las promovieron, de los reclamos expuestos, los escenarios donde se desenvolvieron y de los aliados ganados, así como la co-variación, "principal herramienta analitica de las investigaciones en ciencia social" (Galtung, 1966: 474), de estas variables, las cuales cobrarán inteligibilidad en relación con los hallazgos de las investigaciones preexistentes sobre procesos de lucha concretos y organizaciones estudiantiles.

El texto se encuentra dividido en dos secciones. En primer lugar, nos adentraremos en la identidad de los protagonistas, las tácticas empleadas y los ámbitos donde se gestaron. Luego analizaremos sus demandas y distinguiremos aliados y enemigos. Con estos elementos propondremos a lo largo del trabajo una periodización del movimiento estudiantil

1. Pablo Bonavena (1990-1992), Las luchas estudiantiles en Argentina 1966-1976, Informe de Beca de Perfeccionamiento, Secretaria de Ciencia y Técnica, Universidad de Buenos Aires. [De aquí en más BDB]. Entre 2006 y 2018 sucesivas indagaciones de control en las hemerotecas de la Biblioteca Nacional, la Biblioteca del Congreso de la Nación y la Biblioteca de la Legislatura de la Ciudad de Buenos Aires comprobaron la fiabilidad y representatividad de esta fuente. La base puede consultarse en el área de Conflicto Social del Instituto de Investigaciones Gino Germani de la UBA. 
durante aquella década, donde serán señaladas las disrupciones en los procesos de lucha. Finalmente, en las conclusiones ofreceremos una caracterización general de las tendencias analizadas, el modo en que consideramos más adecuado interpretarlas y las explicaciones e hipótesis plausibles de desplegar.

\section{Protagonistas, tipos de acción y facultades}

La autodenominada "Revolución Argentina" instaurada en 1966 se definió desde sus inicios como una dictadura anticomunista. Cerró el Congreso Nacional, proscribió la actividad de los partidos políticos y, alegando motivos de seguridad nacional, intervino las universidades, anulando el cogobierno y la autonomía. Esta medida despertó honda resistencia entre los estudiantes y profesores reformistas de la UBA. La tristemente célebre "Noche de los Bastones Largos" del 29 de julio fue uno de los más intensos episodios de un acalorado segundo semestre.

Varias aproximaciones generales a la evolución del movimiento estudiantil en aquel período, en su preocupación por explicar la adhesión universitaria al peronismo durante 1973, señalaron la intervención de 1966 como un hito fundante. A partir de la proscripción política en la universidad, ciertos autores imputaron una creciente solidez en el vínculo de los estudiantes con el "pueblo peronista proscrito", sin problematizar el aval justicialista a la flamante dictadura y la designación de algunos de sus cuadros en puestos gubernamentales o del funcionariado universitario. Según su parecer, entre los alumnos comenzó un largo proceso de adscripción al peronismo ("peronización"), que constituyó una de las vías más importantes para la radicalización estudiantil de los 60 y 70. En esta misma postura puede sumarse a Barletta y Tortti (2002). En paralelo, también se insistió en la crisis del reformismo universitario, cuyas ideas y prácticas no eran acordes con una etapa de gran agitación política y social (Sigal, 1991: 71). Este proceso resultaba evidente en la pérdida de protagonismo de los centros y federaciones estudiantiles a manos de las agrupaciones peronistas y de la nueva izquierda en general, de mayor activismo y radicalidad (Altamirano, 2007: 123).

Estudios recientes cuestionaron el vínculo entre radicalización y peronización para los casos de Córdoba, Corrientes y Resistencia, Rosario, Tucumán y La Plata en tiempos de la "Revolución Argentina", es decir en regiones clave donde ocurrieron numerosos alzamientos de masas con participación rutilante del movimiento estudiantil (Millán, 2013a, 2013b, 2017a, 2017b; Nava, 2013).

En el caso de Buenos Aires, sin dudas el epicentro de la experiencia de la izquierda peronista universitaria de 1973, la idea de una conexión entre resistencia a la intervención universitaria y peronización se 
enfrenta con un obstáculo insalvable: las poco relevantes agrupaciones peronistas de la UBA apoyaron el golpe de Estado y la intervención de 1966 (Bonavena, 2000; Califa, 2015). Una excepción resultó el recién conformado Frente de Estudiantes Nacionales (FEN), aunque por entonces su incorporación al peronismo era embrionaria, conservando los lazos con el reformismo y la izquierda de donde provenía su militancia (Califa, 2017).

De todos modos, entre 1966 y 1973 los grupos estudiantiles experimentaron numerosas transformaciones, por lo tanto debería observarse la trayectoria de estos colectivos y su protagonismo en la resistencia contra la dictadura. En tal variable, el código de la investigación reconoce 27 categorias no excluyentes, puesto que una acción puede haber sido protagonizada por más de un grupo estudiantil. Las categorias de la codificación comprendieron los centros y federaciones, las agrupaciones estudiantiles de izquierda a derecha, los cuerpos de delegados y los casos donde, en los diarios relevados, no se consignan más detalles sobre los protagonistas que "estudiantes". En nuestra exposición, a los fines de simplificar la lectura, hemos construido cinco categorias: "Centros y Federaciones", "Agrupaciones Reformistas" (MOR-PC; Franja Morada, MNR, AUN y otras reformistas), "Agrupaciones de Izquierda (FAUDI, TUPAC, TAREA-JSA, TERS, y otras marxistas o anarquistas); "Agrupaciones Peronistas" (FEN, JUP, JUP Lealtad y agrupaciones cristianas como el Humanismo, el Ateneo u otras), "Grupos de Derecha" (Sindicato Universitario de Derecho, CNU, ALN, CEOUP y otros). En el gráfico ${ }^{\circ}$ 1 puede observarse una evolución de los porcentajes de protagonismo de los distintos conglomerados políticos en el conjunto de las acciones del movimiento estudiantil: ${ }^{2}$

Una observación sistemática del desempeño estudiantil arroja un contraste diáfano respecto de las explicaciones ofrecidas en los textos referidos, muchos de ellos considerados como referencias en la temática. Los centros y federaciones estudiantiles reformistas, donde no participaban los peronistas ni los católicos, con excepción del humanismo herido de muerte desde el inicio de la dictadura en 1966, fueron las palancas de las acciones de lucha del movimiento estudiantil de la UBA bajo la "Revolución Argentina". En esta etapa, estas entidades participaron de aproximadamente el $45 \%$ de las acciones, superando el 50\% en 1968, 1972 y 1973. En paralelo, las agrupaciones reformistas, superpuestas

2. En la BDB aparecen acciones estudiantiles con varios protagonistas. Hemos consignado a todos los protagonistas mencionados. El cálculo realizado fue la cantidad de acciones protagonizadas por cada conglomerado en un año, número que contiene casos compartidos, sobre la cantidad total de acciones del movimiento estudiantil en el mismo período y luego multiplicado por cien. No son porcentajes de protagonismo, sino una medición de quiénes estaban en las acciones de lucha del movimiento estudiantil. 


\section{Gráfico $n^{\circ} 1$ \\ Evolución anual del protagonismo en las acciones de lucha estudiantil en la UBA, julio de 1966 a diciembre de 1975}

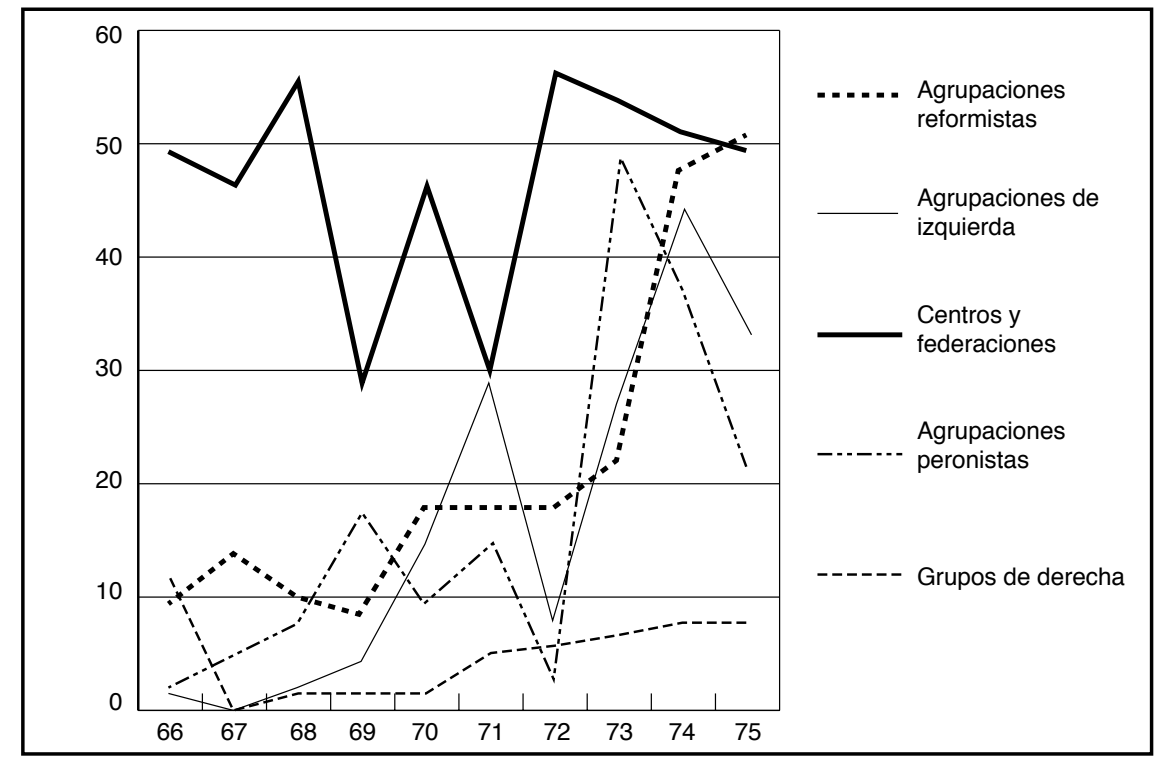

con las anteriores entidades que dirigian, rozaron por sí mismas el 15\%, superándolo siempre desde 1970. Los católicos y los peronistas, un grupo bastante heterogéneo y fragmentado, promediaron poco menos del $14 \%$, entre los cuales se cuentan alineamientos a favor del gobierno de Onganía y la intervención universitaria de 1966. La izquierda marxista fuera del PC promedió un 12\%, llegando a un pico del 30\% en 1971, el año de mayor cantidad de acciones. En esos 12 meses los cuerpos de delegados erigidos en los combates por el ingreso irrestricto a la UBA, que no aparecen en el gráfico dada su escasa importancia estadística global, estuvieron presentes en casi un tercio de las acciones. Por su parte, los grupos de derecha consumaron una media superior al 4\%, ampliando su participación desde 1968 hasta tocar su techo durante el trienio peronista 1973-1976.

Es importante, asimismo, notar que desde 1973 se vislumbra un crecimiento de magnitud en la activación de las agrupaciones peronistas, quienes participaron de casi el 50\% de las acciones, disminuyendo luego al $37 \%$ en 1974 y al 22\% en 1975. El salto inicial con respecto al período anterior y el declive abrupto de 1974 y 1975, años de la represión encabezada por la misión Ivanissevich y del desplazamiento definitivo en la UBA de los funcionarios afines de la Tendencia nombrados 
en 1973 (Bonavena, 2007; Gillespie, 1987: 168 y ss.; Izaguirre, 2011), cuestionan seriamente la idea de una "acumulación de largo plazo" y colocan en primer plano el ejercicio del poder estatal y gubernamental para explicar la peronización estudiantil.

Resulta también importante reconocer la evolución anual en la cantidad de actividades. Su cruce con el protagonismo y la información sobre la conducción de los centros y federaciones nos permitirá comprender no sólo las orientaciones ideológicas, sino la praxis de las principales corrientes. En ese plano, en el gráfico $n^{\circ} 2$ podrá observarse la progresión del total de acciones, de las cuales se restaron las declaraciones y aquellas acciones realizadas en apoyo a las autoridades y/o al gobierno.

La operación de sustracción, realizada tras una ponderación que hizo matemáticamente comparables los valores obtenidos, nos permite observar curvas sumamente diferentes en el trienio peronista. ${ }^{3} \mathrm{La}$ evolución de las acciones totales tiene un pico muy alto en 1966 tras el golpe, desciende bruscamente en 1967 una vez consolidada la intervención, registra un ascenso continuo entre 1968 y 1971, años signados por las revueltas estudiantiles en el mundo y por los "azos" argentinos donde los alumnos participaron activamente, un retraimiento en 1972 con el llamado a elecciones en marcha, un nuevo ascenso entre 1973 y 1974 en medio de las expectativas abiertas tras el retorno democrático y una caída abrupta en 1975, cuando esas ilusiones se frustraron definitivamente con el éxito de la contrainsurgencia en la universidad. Como puede notarse, el ascenso comenzado en 1968 tiene una pendiente notoriamente más inclinada en 1970 y 1971.

Si en esa contabilidad excluimos las declaraciones y comunicados, formas de acción que comprometen un pequeño movimiento de recursos en comparación con la acción de masas, la evolución de la cantidad de acciones del estudiantado de la UBA resulta sustancialmente diferente, puesto que 1972 y 1973 son años de descenso, con un tenue recupero en 1974, que no compensa la merma anterior, y una baja pronunciada en 1975.

Asimismo, para observar la disposición a la confrontación, hemos aislado las peticiones de "apoyo al gobierno y/o a funcionarios". Las acciones orientadas hacia el resguardo del oficialismo suponen un cos-

3. Dado que en una misma acción pueden presentarse varias formas y reclamos, al tiempo que cada categoría de la exposición contiene varias de la codificación, la suma algebraica de los reclamos o de las formas de acción supera el total de hechos. Sin ponderación alguna, en 1973 la cantidad de hechos sin contar las declaraciones y/o los apoyos al gobierno y/o funcionarios es un número menor a cero. Por ello se equipararon los valores de las tres variables en un 100\% hipotético, cuya base fue la cantidad de hechos, y luego se recortaron los excedentes absolutos de $36 \%$ de la cantidad de reclamos y 9,5\% de los tipos de acción. 


\section{Gráfico $\mathrm{n}^{\circ} 2$ \\ Evolución anual de la cantidad de hechos de lucha estudiantil en la UBA, julio de 1966 a diciembre de 1975}

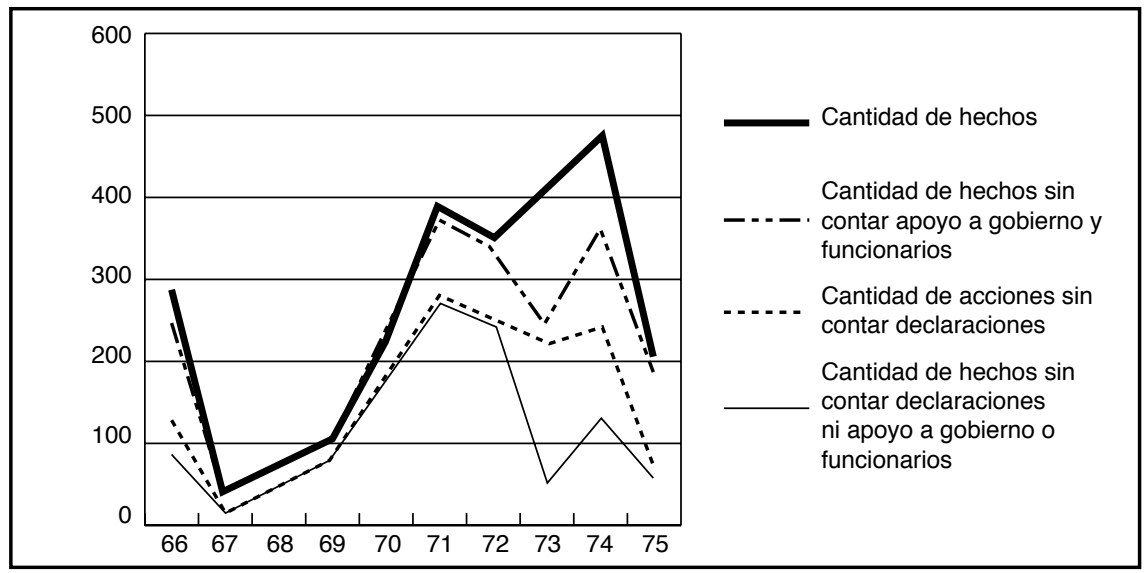

to de movilización mucho menor que un enfrentamiento directo, pues refieren a pugnas mediadas por otros actores, como el Poder Ejecutivo. En ese punto vemos que el retraimiento interanual de 1973 es el más pronunciado de nuestras líneas de evolución. Con posterioridad, se registra un notorio salto interanual en 1974, sobre todo a causa del auge de la violencia contrainsurgente bajo la misión Ivanissevich (Rodríguez, 2016), sin que por ello se alcancen los niveles de activismo de 1970-1972.

Por otro lado, no sólo interesa observar la evolución cuantitativa de acciones con estos elementos aislados, sino mensurar su distancia con un análisis que no atienda a estos aspectos. En tal sentido, la observación de todos estos factores no muestra una relación entre "peronización" e incremento en el compromiso y la radicalidad del movimiento estudiantil. La retraída leve de 1972 se volvió, en contraste con ideas muy corrientes, en una pendiente pronunciada con el peronismo en el poder, sin recuperarse los guarismos de los años siguientes al Cordobazo.

Una exploración más detallada por las formas de acción contribuye a reparar con detenimiento en aspectos relativos al compromiso, la disposición al enfrentamiento, la relación con las instituciones y la violencia. En la variable formas de acción se clasificaron los hechos en 17 categorias, las cuales fueron reagrupadas en cuatro categorias complejas: "Declaraciones y/o comunicados"; "Acción institucionalizada" (conferencia de prensa, acto, asamblea, huelga de hambre, huelga universitaria de escala nacional, local o por unidad académica); "Acción directa sin violencia" (marcha, movilización, concentración, toma sin control del 
edificio); "Acción directa con violencia" (acto relámpago, enfrentamientos con la policía, barricada, toma con control del edificio, detonación de explosivos, ataque armado). Debe tenerse en cuenta que se han producido al menos 240 casos donde una acción se convirtió en otra, por ejemplo un acto que trocó en asamblea, una asamblea transformada en una marcha o una movilización que derivó en enfrentamientos con la policía. En el gráfico $n^{\circ} 3$ puede observarse la evolución de las distintas formas de acción desplegadas por el movimiento estudiantil de la UBA.

En una lectura de este gráfico advertimos que, con la excepción de la enorme cantidad de declaraciones contra la intervención de 1966, hasta 1969 las formas de acción están relativamente empatadas. Sin embargo, desde ese momento empezó a cobrar más importancia la acción dentro de los marcos institucionales. Esta tendencia puede sorprender si no se tiene en cuenta, como veremos en el próximo apartado, que después del Cordobazo los requerimientos universitarios y antirrepresivos ocuparon el centro de la agenda del movimiento estudiantil de la UBA y de otras regiones del país (Millán, 2013a, 2013b, 2017a, 2017b; Nava, 2013). Dentro suyo, el reclamo por el ingreso irrestricto devino uno de los más importantes, logrando su conquista parcial y, por ende, el retroceso de una iniciativa fundamental de la política universitaria de la dictadura (Califa y Seia, 2017).

La segunda cuestión sobresaliente es el peso de las declaraciones entre las formas de acción estudiantil durante el trienio peronista, especialmente en 1973 y 1974. La tensión de Montoneros entre la negociación, la participación, la movilización y el enfrentamiento (Gillespie, 1987: 161 y ss.) impregnó al movimiento estudiantil conducido por su agrupación afin, la JUP, tanto antes como después de la ruptura del grupo Lealtad, en el verano de 1974. De esa manera, las declaraciones eran formas de acción que no implicaban, usualmente, una práctica colectiva que fracturase ciertos acuerdos intraperonistas, pero que permitian fijar posición sobre problemas de la cotidianidad universitaria. Asimismo, las declaraciones y comunicados eran el vehículo de expresión para intenciones de transformación universitaria, textos que

4. Entre las categorias "acción institucionalizada" (AI) y "acción directa sin violencia" (AD s/v) hay tipos de hechos que no pueden clasificarse sin controversias. Puesto que privilegiamos diferenciar las acciones directas en función del ejercicio de la violencia, hemos colocado las huelgas de hambre y la huelgas estudiantiles, no equiparable al instituto de la huelga de los asalariados, dentro de AI. En todo el período la AI suma 1.046 casos y la AD s/v 201; registrando 13 huelgas de hambre y 65 huelgas estudiantiles. Aunque un cambio de categoría de estos hechos reduciria la actual asimetría en favor de la AI de 5,20 a 3,46 veces las AD s/v, la evolución de las distribuciones anuales no experimenta cambios de tendencia. 


\section{Gráfico $n^{\circ} 3$}

Cantidad anual de acciones de lucha estudiantil en la UBA por año según formas, julio de 1966 a diciembre de 1975

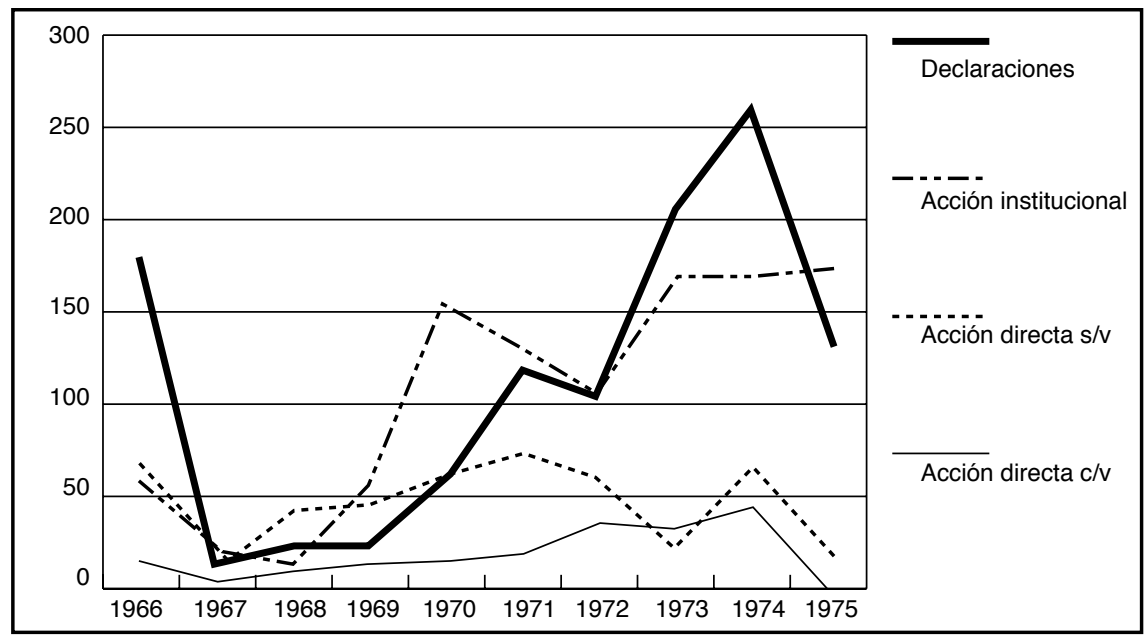

dificilmente podrian considerarse un proyecto de universidad, puesto que sus enunciantes no contaban con semejante capacidad de acción.

En muchas de esas declaraciones también se vertían críticas al reformismo y a la izquierda universitaria, a pesar de que estos conglomerados acompañaban a la JUP en sus enfrentamientos con la ortodoxia partidaria, produciendo dificultades para la unidad estudiantil. Si excluimos los hechos realizados por grupos de derecha, las menciones a otros grupos combativos como enemigos por parte de los estudiantes reconocen una enorme alza durante el trienio peronista, cuando concentró 73 de los 80 casos, teniendo su pico entre 1973 y 1974.

La tercera observación, que se desprende de las dos primeras, es que la acción directa perdió importancia durante la fase final de la "Revolución Argentina" y, más aun, durante la etapa peronista. Al respecto vale una aclaración: tanto la acción directa sin violencia como aquella que la involucró, presentan una curva de ascenso muy tenue pero sostenido desde 1968.

En el caso de la que implica el uso de la violencia existe un declive en 1972 y una fuerte retracción en 1973. El repunte de 1974 se debe a la violencia de los grupos de derecha, en pleno ascenso. La inclinación a la baja de 1975 se explica por cierta retracción en las actividades paramilitares en la UBA, tras su auge y éxito en la conformación de un clima de terror durante el rectorado de Alberto Ottalagano (Califa y Mi- 
llán, 2016a, 2016b; Izaguirre, 2011). Esto quiere decir que hasta 1971 el crecimiento del ejercicio de la violencia está en estrecha relación con la radicalización estudiantil, y a partir de 1974 con la represión paraestatal.

En cuanto al balance de la acción directa no violenta, el crecimiento tenue en la cantidad de este tipo de prácticas prosiguió hasta 1972, tuvo una pequeña mengua en 1973, un repunte notorio en 1974 y un fuerte repliegue en 1975. Como se ha afirmado anteriormente, el proceso de institucionalización de la acción colectiva estudiantil durante el tercer peronismo tuvo como efecto el achicamiento en la cantidad y el peso de la acción directa. El desplome de 1975 se explica en buena medida por la represión precedente, asi como por el reposicionamiento del radicalismo y la recuperación de las posiciones del MOR en una etapa signada por la búsqueda comunista de la convergencia cívico-militar (Casola, 2015).

En este análisis de la trayectoria del movimiento estudiantil de la UBA también resulta importante desagregar los enfrentamientos por facultad y año, ejercicio que precisa los actores. En la tabla $n^{\circ} 1$ se observan las frecuencias obtenidas.

El primer dato relevante, que no concita asombro, es que Filosofia y Letras fue la facultad de más apariciones en la base de datos y, dada su distancia con las demás, resultó la unidad académica de la UBA

Tabla $n^{\circ} 1$

Cantidad de acciones estudiantiles por Facultad de la Universidad de Buenos Aires, julio de 1966 - diciembre de 1975*

\begin{tabular}{|r|r|r|r|r|r|r|r|r|r|}
\hline Año & \multicolumn{1}{|c|}{ D } & \multicolumn{1}{c|}{ E } & \multicolumn{1}{c|}{ M } & AU & \multicolumn{1}{|c|}{ I } & \multicolumn{1}{|c|}{ F } & AV & EN & \multicolumn{1}{c|}{ O } \\
\hline 1966 & 11 & 27 & 11 & 20 & 30 & 25 & 7 & 20 & 11 \\
\hline 1967 & 1 & 4 & 2 & 1 & 0 & 8 & 0 & 10 & 0 \\
\hline 1968 & 3 & 1 & 3 & 0 & 0 & 3 & 0 & 1 & 1 \\
\hline 1969 & 12 & 7 & 6 & 5 & 4 & 11 & 1 & 6 & 2 \\
\hline 1970 & 21 & 14 & 14 & 20 & 11 & 52 & 10 & 33 & 5 \\
\hline 1971 & 58 & 39 & 16 & 54 & 24 & 113 & 6 & 14 & 0 \\
\hline 1972 & 39 & 32 & 80 & 29 & 13 & 55 & 40 & 23 & 12 \\
\hline 1973 & 45 & 29 & 47 & 17 & 15 & 33 & 32 & 30 & 28 \\
\hline 1974 & 61 & 43 & 46 & 36 & 38 & 55 & 33 & 38 & 57 \\
\hline 1975 & 13 & 14 & 14 & 7 & 11 & 23 & 4 & 6 & 12 \\
\hline Total & 264 & 210 & 239 & 189 & 146 & 378 & 133 & 181 & 128 \\
\hline
\end{tabular}

* Cuando consideramos las facultades, hemos clasificado como (D) Derecho y Ciencias Sociales, (E) Ciencias Económicas, (M) Medicina, (AU) Arquitectura y Urbanismo, (I) Ingeniería, (F) Filosofía y Letras, luego también Psicología y Sociología, (AV) Agronomía y luego también Veterinaria, (EN) Ciencias Exactas y Naturales y $(\mathrm{O})$ otros: Odontología, Farmacia y Bioquímica, Colegio Nacional Buenos Aires y Escuela Superior de Comercio Carlos Pellegrini, Rectorado y otras dependencias administrativas. 
con mayor activismo. Con "un cuerpo de distancia" le siguen Derecho y Medicina, un poco más atrás Ciencias Económicas y luego, casi en el mismo nivel, Arquitectura y Urbanismo y Ciencias Exactas y Naturales. Cierran la lista Ingenieria y Agronomía-Veterinaria, muy cerca de la cifra de "otros". No obstante, debe ponderarse la cantidad de cursantes, lo cual conlleva a redimensionar la militancia de las últimas facultades mencionadas.

Con todo, Filosofia y Letras resultó la más activa entre 1970 y 1971, los años de mayor movilización. En efecto, propició uno de los escenarios donde tuvieron amplio desarrollo los cuerpos de delegados, llegando a producirse el fenómeno del "doble poder" (Bonavena, 1997). Asimismo, esta unidad académica ha sido un terreno fértil para casi todo tipo de experiencias políticas: convivian incómodamente los docentes peronistas de las "cátedras nacionales", ingresados o ascendidos con el golpe de Estado y la intervención de la que luego algunos tomaron distancia, con la dirección del centro estudiantil de los "izquierdistas" de FAUDI, quienes todavia no se habían reconocido como maoístas pero ya integraban las filas de novel PCR. Existia, incluso, un activo grupo de docentes marxistas, algunos de ellos nucleados en la Agrupación 29 de Mayo, integrada por independientes de izquierda junto al PCR y Vanguardia Comunista (Bonavena, 1997: 167). Resulta fundamental recordar que las "cátedras nacionales" no integraban el movimiento estudiantil, y su relación con los cuerpos de delegados tuvo idas y vueltas, siendo lejana en su año de auge. ${ }^{5}$

Por otra parte, entre 1971 y 1972 el MOR conquistó casi todos los centros de estudiantes de la UBA. Tras la ruptura de 1967, de donde habia emergido el FAUDI-PCR, aquellas victorias significaban una rauda recuperación de la influencia del PC en la universidad y dentro del movimiento estudiantil (Califa, 2016b). La apuesta por el gremialismo universitario en el período posterior al Cordobazo le granjeó grandes adhesiones entre los alumnos porque motorizaba, como veremos, los principales reclamos del movimiento estudiantil.

Asimismo, si volvemos al gráfico $\mathrm{n}^{\circ} 1$ donde se detalla la participación de los distintos conglomerados estudiantiles en las acciones de lucha, observamos que las agrupaciones de izquierda (excluido el MOR-PC) y los centros y federaciones compartieron el liderazgo en 1971, pero al año siguiente el segundo de estos bloques despegó muy por encima de todos los demás. Hay facultades donde bajo la nueva dirección comunista decrecieron tenuemente la cantidad de hechos de lucha, como Filosofia y Letras, Arquitectura y Urbanismo, Derecho y Ciencias Eco-

5. Véase "De base y con Perón. Un documento autocrítico de las ex Cátedras Nacionales", en Antropología del Tercer Mundo, n 10, junio de 1972, pp. 27-34. 
nómicas. En otras, como Medicina y Ciencias Exactas y Naturales, se registró una pronunciada tendencia alcista. Si volvemos la mirada al gráfico $\mathrm{n}^{\circ} 2$ notaremos que el resultado global de 1972, donde también intervenía el horizonte de una salida electoral inminente, ha sido el de una reducción de la acción estudiantil y, dentro de esta tendencia, un llamativo achicamiento de la primacía de la acción institucional sobre la acción directa.

Por otra parte, en 1973 resulta notoria la continuidad del decaimiento en las acciones, que un año después repuntaron en todas las facultades (excepto Agronomia y Veterinaria), en gran medida a raíz de la creciente represión y del desplazamiento de los funcionarios ligados a la Tendencia. Las dos terceras partes de las acciones de lucha estudiantil de 1974 se concentraron en el segundo semestre, después de fallecido Perón, siendo las jornadas más intensas, con una media semanal de 14,88 acciones, las comprendidas entre el 1 de julio y el discurso del Ministro de Educación Oscar Ivanissevich en el Teatro Colón, el 10 de septiembre. Allí lanzó la "Misión Ivanissevich", con una nueva intervención universitaria fundamentada en la presencia de una presunta "subversión contra los poderes de la Nación", figura contemplada en el artículo $\mathrm{n}^{\circ} 5$ de la Ley Universitaria 20.654 (conocida como "Ley Taiana"), de febrero de 1974, en plena escalada represiva bajo la tercera presidencia de Perón (Buchbinder, 2014: 195 y ss.).

En este marco, los tres reclamos principales fueron el rechazo a la nueva política universitaria, el cese de la represión que la acompañó y el apoyo a las autoridades desplazadas. Para profundizar en estos aspectos del movimiento estudiantil de la UBA será necesario continuar su análisis en un apartado que relacione los reclamos, los escenarios y los aliados de este heterogéneo y disputado sujeto colectivo.

\section{Reclamos, escenarios y aliados del movimiento estudiantil}

El análisis de un movimiento de lucha durante un periodo tan prolongado y cambiante, como el que nos toca escrutar, requiere precisar los reclamos impulsados. En tal variable identificamos 13 categorias, que a su vez fueron reagrupadas en cinco: "Reclamos académico-universitarios" (autonomía y cogobierno, cuestiones académicas, bienestar estudiantil, ingreso irrestricto); "Política universitaria" (cuestionamiento contra funcionarios y/o profesores, crítica de la política universitaria gubernamental); "Cuestiones politicas" (contra medidas y acciones políticas en el escenario nacional y/o internacional, solidaridad con otras luchas, memoria-homenaje a mártires), "Antirrepresivo", "Apoyo a gobierno y/o funcionario" (apoyo a funcionario, apoyo a la politica 
educativa del gobierno o al gobierno en general). En el gráfico $n^{\circ} 4$ puede apreciarse su evolución anual.

\section{Gráfico $n^{\circ} 4$ \\ Reclamos del movimiento estudiantil de la UBA, julio de 1966 a diciembre de 1975}

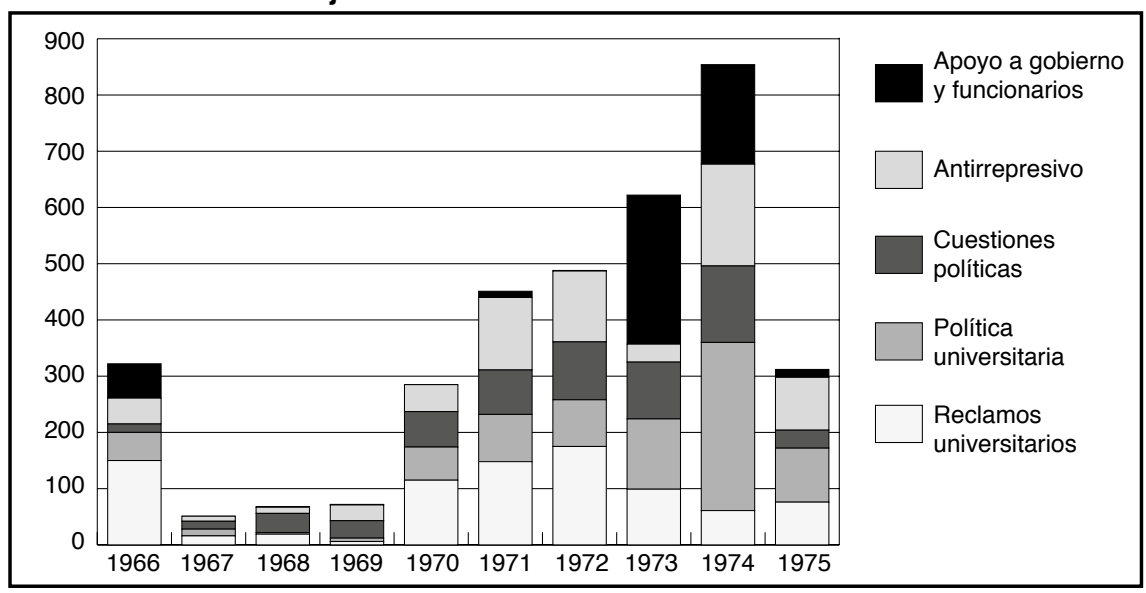

Sobre esta variable existen nociones previas de amplia adhesión en el campo académico y en las memorias militantes. Por ejemplo, Beatriz Sarlo ha considerado que la radicalización de los universitarios en los 60 y 70 condujo a "posiciones cada vez más políticas en términos generales y menos específicas en lo que refiera a la universidad" (2001: 102). La distribución de los valores encontrados para cada categoría de reclamos, al igual que los estudios previos sobre otras regiones durante la "Revolución Argentina" (Millán, 2013a, 2013b, 2017a, 2017b; Califa y Seia, 2017; Nava, 2013), demuestran que estas ideas deben reconsiderarse.

En contraste con las mismas, en el conjunto de la década 1966-1975 los reclamos universitarios son los que registran más menciones por el movimiento estudiantil de la UBA (865), seguidos de los cuestionamientos a los aspectos parciales o del conjunto de la politica universitaria gubernamental (817). Juntos representan un 44,05\% del total.

Estas cifras, junto al declive de la disposición estudiantil al enfrentamiento durante el trienio peronista observada en el apartado anterior, también pueden conducirnos a cuestionar las influyentes tesis de Juan Carlos Portantiero, quien sostenía que las movilizaciones estudiantiles de los 60 y 70 se debian a la incapacidad estructural del capitalismo dependiente para otorgar buenos empleos y ascenso social a los universi- 
tarios (1978: 14 y ss.). De ser cierto, ¿por qué los estudiantes centraban sus reclamos en las cuestiones universitarias y no en las políticas? A su vez, ¿por qué no hubo mayores enfrentamientos estudiantiles cuando las dificultades económicas fueron mayores, como en 1974 y 1975 ?

Entrando en detalle sobre los reclamos, visualizamos que desde 1966 hasta 1972, con la excepción de 1969, los reclamos universitarios y contra la política universitaria oficial fueron el centro de las preocupaciones del movimiento estudiantil, algo que volvió a repetirse en 1974 y 1975. Frente a la intervención universitaria, la defensa de la autonomía y el cogobierno fueron las reivindicaciones más extendidas, abarcando el $36,69 \%$ de las menciones. Luego, en el agitado ciclo comprendido entre 1970 y 1972 , se vivió un auge de las demandas académicas, los cuales abarcaron anualmente un $17,58 \%, 20,81 \%$ y $26,33 \%$.

Estos mismos años registran un crecimiento de las protestas contra actitudes de docentes adictos a la dictadura y/o el pedido de renuncia, extensible a funcionarios universitarios y del Ministerio de Educación, asi como pronunciamientos contra la política universitaria. Mientras que la "Política universitaria" concitó un 8,21\% de menciones en 1969, en 1970 se elevó a un 20,34\%, para tener caídas en los dos años siguientes y retomar vuelo durante el trienio peronista con $18,76 \%, 31,37 \%$ y $27,98 \%$. La peculiaridad, que puede llamar a sorpresa, es que en los dos últimos años estos motivos sumaron más menciones que las cuestiones antirrepresivas, sin dudas un reclamo urgente en vista de la magnitud de la represión contra el movimiento estudiantil.

En cuanto a este eje reivindicativo, el tercero en importancia para esta dilatada década del movimiento estudiantil de la UBA, su evolución se precipitó en 1971, cayó abruptamente dos años más tarde, alcanzó un récord en 1974 y se redujo a la mitad al año siguiente, en una proporción sensiblemente menor que la registrada para el descenso en la cantidad de acciones estudiantiles y quedando prácticamente igualado con las críticas contra la política universitaria. Para el final de la "Revolución Argentina", otros estudios registran una evolución similar de esta demanda (Millán, 2013a, 2013b, 2017a, 2017b). Una de las variables con mayor poder explicativo refiere al comienzo durante 1971, en tiempos del Gran Acuerdo Nacional, de las acciones parapoliciales y/o paraestatales contra el movimiento estudiantil; una práctica que no cesó con el advenimiento de un gobierno formalmente constitucional en 1973, y que se disparó entre 1974 y 1975 (Califa y Millán, 2016a, 2016b; Franco, 2012: 59-128; Bonavena et al., 1998: 132-136).

Por otra parte, frente a una de las ideas más difundidas: que la "politización" abarcó y/o inundó todos los rincones de la práctica del movimiento estudiantil, aquí ofrecemos elementos para pensar la cuestión con más matices. Las menciones y/o fundamentaciones de la acción de 
los alumnos basadas en temas de la política nacional (extrauniversitaria) e internacional, en solidaridad con otros colectivos como el movimiento obrero y las actividades de memoria y/o homenaje, abarcaron apenas en promedio el $15,92 \%$ durante todo el periodo. Los años de mayor gravitación fueron los comprendidos hasta el Cordobazo, cuando representaron $27,45 \%, 49,27 \%$ y 42,46\% de los reclamos en 1967, 1968 y 1969. Posteriormente se produjo una involución cuantitativa de estas motivaciones ubicándolas en un rango de entre un $15 \%$ y un $20 \%$ de las menciones, cayendo al 9,32\% en 1975. Estos números pueden cuestionar también las acreditadas consideraciones de Alain Touraine, quien afirmaba que la radicalización estudiantil era una variable dependiente del dirigismo estatal y la rigidez institucional (1971: 125 y ss.). De ser así ¿por qué el movimiento estudiantil ingresó en una fase de moderación durante la misión Ivanissevich? Las proposiciones del sociólogo francés constituyen, entonces, una generalización empírica temprana, tan sugerente como cuestionable.

Retornando a las cifras de los reclamos políticos del movimiento estudiantil de la UBA, debe recordarse que en los primeros dos años del trienio peronista las acciones en apoyo a las autoridades representaron un $39,78 \%$ en 1973 y un $18,57 \%$ de las fundamentaciones del accionar estudiantil. En 1973 y 1974 el movimiento estudiantil mantuvo la tasa de reclamos "políticos", pero el peso de las declaraciones aumentó enormemente dentro de las formas de acción y sus preocupaciones estuvieron centradas en el apoyo a funcionarios y/o al gobierno, una motivación opuesta por el vértice a la ocurrida en los últimos tramos de la autoproclamada "Revolución Argentina". Asumimos, en esta dirección, que durante el trienio peronista el movimiento estudiantil resignó buena parte de su disposición al enfrentamiento y su autonomía.

En cuanto a los escenarios donde ocurrieron las acciones, originalmente fueron clasificados ocho ítems, pero luego, en función de la distribución de los casos, resultaron simplificados a la mitad: "Universidad", "Calles y/o espacio público", "Locales de partidos políticos" y "Otros" (locales sindicales, locales y/o domicilios privados, teatros, cines, edificios de entidades deportivas, religiosas, profesionales u otras actividades civiles).

Como se desprende del gráfico $\mathrm{n}^{\circ} 5$, sólo durante 1968 las calles fueron el escenario preponderante de la acción estudiantil. Se trató, como se sostuvo, del año en que comenzó a recuperarse la oposición estudiantil a la dictadura. Desde entonces la acción callejera cayó hasta 1970 para crecer durante dos años, cuando a mediados de 1972 inició su desbarranco. Por su parte, las acciones en la universidad, muy por encima, registraron una dinámica inversa y sólo empalmaron con la anterior en 1974, cuando se afianzó la represión universitaria. En ese 


\section{Gráfico $n^{\circ} 5$}

Evolución del porcentaje de los escenarios de la acción estudiantil

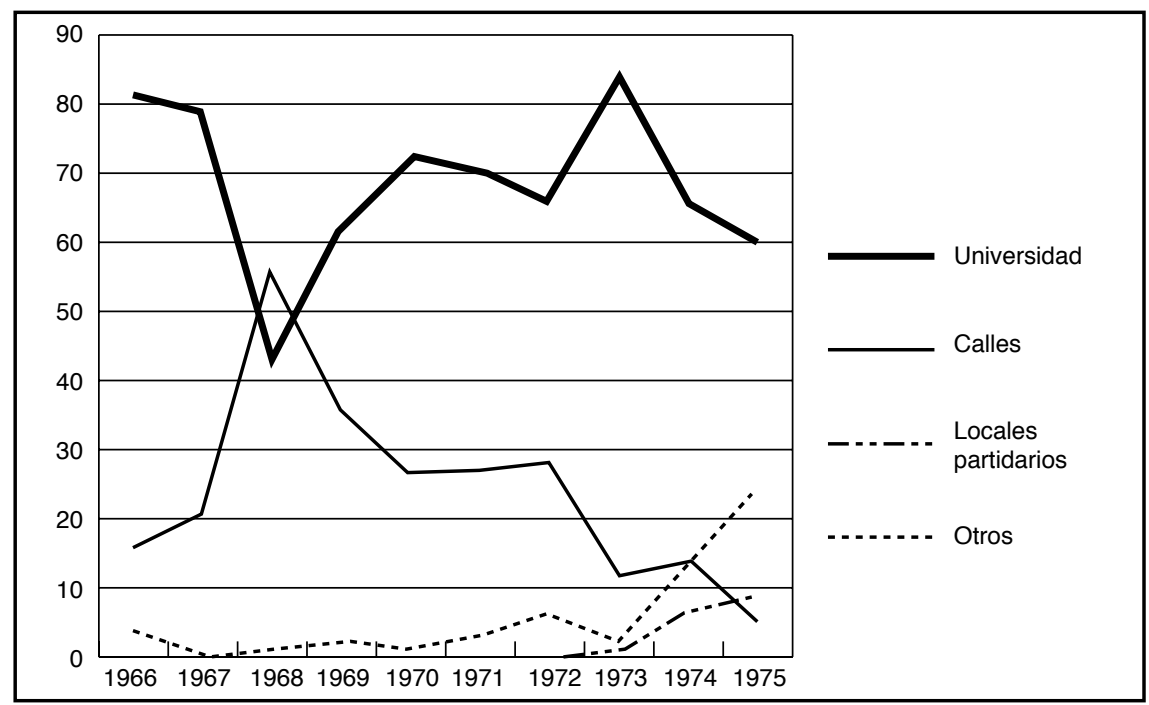

marco, los locales partidarios, hasta aquí un escenario marginal de la lucha estudiantil, así como el resto de los espacios contemplados bajo la categoria "otros", adquirieron relieves trascendentes como asiento de las acciones de lucha, centralmente charlas y conferencias.

No creemos que sea propicio entender sin más un escenario como antitesis del otro, las calles frente a las aulas, sino como complementarios. Sin embargo, la caída de la acción callejera, por más que se mantenga o aumente la acción en las aulas, es indicativa de una pérdida de protagonismo público de la acción más disruptiva. En ese sentido, se confirman las tendencias que venimos observando: mientras que el inmediato post Cordobazo fue un período de ascenso de la radicalización, con una creciente importancia de la acción callejera, la "primavera camporista" confinó al movimiento estudiantil a su lugar de pertenencia "natural": las facultades.

Tales escenarios de la acción se correlacionan, finalmente, con los aliados ganados. La clasificación inicial de nueve categorías aquí es presentada, en el horizonte de abreviar y haciendo caso de la distribución de los valores, en "Docentes", "Trabajadores" y "Partidos Politicos", por lejos las más conspicuas (gráfico ${ }^{\circ}{ }^{6}$ ).

Nuevamente, 1968 es el año donde se produce un quiebre, sobresaliendo la unidad con los trabajadores. La Confederación General de 


\section{Gráfico $n^{\circ} 6$ \\ Acciones del movimiento estudiantil de la UBA con aliados, julio de 1966 a diciembre de 1975}

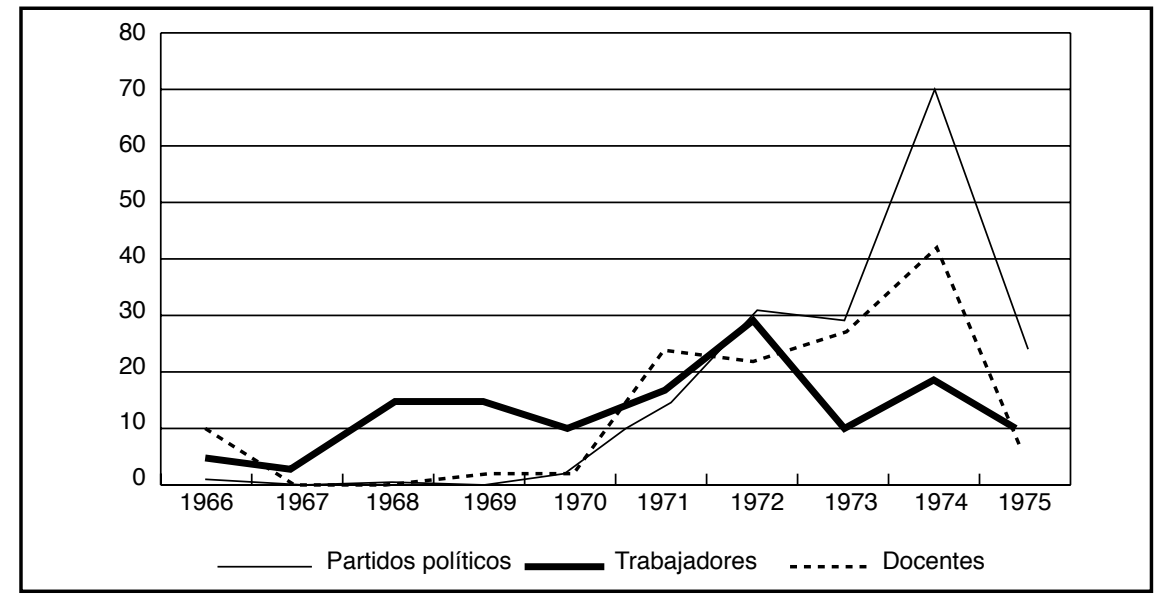

Trabajadores Argentinos (CGTA) propició acciones conjuntas con los estudiantes, a los que buscó tanto como fue requerida por éstos (Gordillo, 2007: 345; Califa, 2016a: 146 y ss.). Sin embargo, en Buenos Aires esta central sindical rápidamente se vino a pique, dejando a los estudiantes porteños sin una referencia institucional tan relevante en el mundo obrero. Pese a ello, el declive registrado en las acciones posterior al traspié de la CGTA mostró un repunte en la nueva década, que alcanzó su pico durante 1972. En esos años el aliado obrero fue en gran medida el clasismo, una corriente beligerante en pleno auge. Sin tener la preminencia que alcanzó en otras regiones argentinas, esta alianza también se tejió en la UBA.

Desde la llegada del peronismo al poder, sin embargo, se contrajo la alianza obrero-estudiantil. Este hecho, a la luz de la retórica exuberante que presenta al peronismo como una puerta de acceso al pueblo real y sus luchas, resulta una evidencia en sentido contrario. Podemos destacar al respecto los alineamientos en torno al llamado "Pacto Social", que tuvo la anuencia de la Tendencia durante un importante lapso de tiempo (Gillespie, 1987: 178-180). Ni siquiera la recuperación de 1974, en buena medida fruto de los grupos de izquierda disidentes que apoyaron las luchas obreras en ascenso y de la expansión de la Juventud Trabajadora Peronista, revirtió la caída.

Pareciera contradictorio con lo anterior que la alianza gestada con los docentes de la UBA, en pleno ascenso desde 1970 llegase a su cús- 
pide a partir del retorno constitucional. Sin embargo, este dato leído a la luz del contexto universitario no es tan llamativo: tras el entusiasta apoyo que concitó entre estudiantes y docentes la llegada de Cámpora a la presidencia y de Rodolfo Puiggrós al rectorado de la UBA, durante el año siguiente el gobierno peronista cesó a muchos de estos docentes. En ese sentido, 1974 reflejó una alianza que, con escaso éxito en la defensa de los expulsados, se derrumbó en 1975 cuando la universidad fue prácticamente vaciada de opositores en ese claustro.

Finalmente, la curva de ascenso que grafica la creciente importancia de los partidos políticos responde a un criterio similar. Cuando arreció la represión y se hizo imposible el activismo en los edificios universitarios, los locales partidarios, sobre todo de la UCR, se convirtieron en los refugios, verdaderamente condicionantes, de la acción estudiantil. El precipicio de 1975 está en sintonía con una desorganización general de la izquierda estudiantil considerada con amplitud, la que, sin ser total, resultó irreversible. Se clausuró así un período central de la historia del movimiento estudiantil de la UBA.

\section{Conclusiones}

En este trabajo recorrimos concisa y sistemáticamente una extensa, cambiante e intensa década de luchas del movimiento estudiantil de la UBA. Al igual que en el conjunto del país, en la universidad los años que mediaron entre los golpes de Estado de 1966 y 1976 fueron un período de álgidas confrontaciones.

A diferencia de los análisis construidos sobre lo discursivo y lo simbólico, nuestra perspectiva epistemológica sostiene que los procesos sociales y la subjetividad se comprenden más acabadamente otorgando centralidad no a "lo que los hombres dicen, piensan, o imaginan" (Marx y Engels, 2004: 18), sino a lo que hacen. No se trata de borrar la dimensión discursiva, más estrecha que la subjetiva, sino de asignarle un peso explicativo más acorde a su importancia en las confrontaciones histórico-concretas.

Por ello construimos un registro, con numerosas fuentes del período, de los enfrentamientos llevados adelante por los distintos actores que constituyeron el movimiento estudiantil. Se trató de 2.549 hechos, dentro de los cuales distinguimos numerosas variables con el objetivo de comprender las formas de acción y sus protagonistas, mensurar los ciclos de movilización y ofrecer tanto una descripción como una explicación del proceso de radicalización.

La matriz teórico-metodológica empleada para elaborar y analizar los datos nos permite arribar a conclusiones que indudablemente chocan con otras aproximaciones sobre el movimiento estudiantil y la politica 
universitaria en los 60 y 70. Con una estrategia metodológica cuantitativa, este artículo condensa muchos hallazgos de investigaciones sobre procesos más acotados, donde fue señalado que el grueso del catolicismo y del peronismo apoyaron el golpe de Estado de 1966 y la intervención universitaria, que su pasaje a la oposición fue contradictorio y tardío (algunos en 1968, otros en 1969), que para 1972 estaba integrado por grupos que se avenían con la salida electoral pregonada con el Gran Acuerdo Nacional. Las pobres cifras de la cantidad de acciones de resistencia estudiantil católica y/o peronista contra la "Revolución Argentina" se explican en el marco de sus alineamientos políticos y de sus flaquezas organizativas. En tal sentido, resulta ilustrativo el armado oportunista del Frejuli en 1973 (advertido por numerosos contemporáneos), minado por choques sangrientos desde la campaña electoral y destruido por sus integrantes durante los primeros días del gobierno de Cámpora en acontecimientos como el Devotazo y la Masacre de Ezeiza. Por tales razones invitamos a pensar criticamente ideas tan difundidas como la "crisis del reformismo", la "peronización estudiantil", el "auge de la nueva izquierda" y el "declive de la izquierda tradicional entre los alumnos".

Nuestra aproximación al problema convoca a cimentar, por el contrario, una periodización alternativa del proceso de radicalización estudiantil, observando no solamente los términos ideológicos presentes en declaraciones, sino más bien la capacidad de participar e incidir en la dinámica de la contienda política desde la acción colectiva. De acuerdo con nuestra perspectiva, el ciclo de auge de las luchas estudiantiles se caracteriza por un protagonismo central del reformismo y la izquierda universitaria. Las corrientes de estas orientaciones, así como los centros y federaciones, contaban con la mayor tradición y continuidad organizativa entre las opciones estudiantiles. Usualmente presentaban una nítida identidad laica frente a una dictadura católica, contra la cual ostentaban una actitud consecuente de enfrentamiento desde el primer momento. Asimismo, en su mayoría buscaron vías para conciliar la lucha reivindicativa con los grandes temas de la politica en general. Dentro del reformismo se destacaron las agrupaciones del PC, que concentraron 302 de las 635 acciones del reformismo en el período ( $\sin$ contar las realizadas por los centros estudiantiles que dirigian). Se trataba de la única fuerza estudiantil que contaba con el respaldo de un verdadero partido político adiestrado en el trabajo clandestino, legal e ilegal, que volcó cuadros de su dirección para la reconstrucción de su corriente universitaria tras la ruptura de 1967, con más de una década de intenso trabajo universitario, intelectual y cultural en ese ámbito. Como se comprende, nada de esto se podía decir para el radicalismo, y 
mucho menos el peronismo, profundamente dividido y con numerosos funcionarios en el régimen.

Posteriormente, el trienio peronista 1973-1976 fue un periodo de retraimiento en la disposición al enfrentamiento del movimiento estudiantil y no de potenciación, como suele afirmarse. Más allá del fragor de las declaraciones y actos de apoyo al gobierno, las acciones de lucha decayeron en comparación de los años anteriores. El consenso que generó el oficialismo en las filas estudiantiles, no sólo peronistas, puso freno al ascenso estudiantil de los años previos, factor que se combinó con errores de análisis de situación y falencias en la fundamentación de las prácticas políticas. En tal sentido, resulta dificil sostener la idea de la radicalización estudiantil a causa del influjo del peronismo y, en menor medida, de la nueva izquierda. Este proceso de declive se revirtió parcialmente en 1974, pero ya en un contexto donde la represión estatal y paraestatal se consolidó y resultó inviable plasmar el programa acuñado durante años de luchas. Entonces, los sueños revolucionarios de la izquierda estudiantil resultaron carcomidos por otra realidad: las tinieblas de la contrarrevolución acompañada por gran cantidad de complicidades que aún hoy es menester denunciar.

\section{Bibliografia}

Altamirano, Carlos (2007), Bajo el signo de las masas (1943-1973), Buenos Aires: Emecé.

Barletta, Ana (2001), "Peronización de los universitarios (1966-1973). Elementos para rastrear la constitución de una política universitaria peronista", Pensamiento Universitario, $\mathrm{n}^{\circ}$ 9, Buenos Aires, pp. 82-89.

Barletta, Ana y Maria Tortti (2002), "Desperonización y peronización en la universidad en los comienzos de la partidización de la vida universitaria", en Pedro Krotch (org.), La universidad cautiva: legados, marcas y horizontes, La Plata: Al Margen.

Bonavena, Pablo (1997), "El cuerpo de delegados como forma organizativa del movimiento estudiantil. El "doble poder" de Filosofia y Letras-UBA", Lucha de Clases, $\mathrm{n}^{\circ}$ 1, Buenos Aires, pp. 161-194.

- (2000), "Apuntes sobre las organizaciones politicas y estudiantiles universitarias que apoyaron a la Revolución Argentina", ponencia presentada en las IV Jornadas de Sociología: Reconstrucción de la Voluntad Sociológica, Buenos Aires: FSOC-UBA.

- (2007), "El rector que no fue. La lucha de los estudiantes de la UBA contra la designación del odontólogo Alberto Banfi en octubre de 1973", en Pablo Bonavena, Juan Califa y Mariano Millán (comps.), El movimiento estudiantil argentino. Historias con presente, Buenos Aires: Cooperativas. Carrera de Sociologia, pp. 229-244. 
Bonavena, Pablo, et al. (1998), Origenes y desarrollo de la guerra civil en Argentina (1966-1976), Buenos Aires: EUDEBA.

Buchbinder, Pablo (2014), "La Universidad y el tercer peronismo. Notas sobre el debate parlamentario en torno a la Ley Taiana", en Mariano Millán (comp.), Universidad, politica y movimiento estudiantil en Argentina (entre la "Revolución Libertadora" y la democracia del 83), Buenos Aires: Final Abierto, pp. 183-201.

Califa, Juan (2015), “A los golpes con el golpe. El movimiento estudiantil frente a la intervención de la Universidad de Buenos Aires, 1966", Conflicto Social, $\mathrm{n}^{\circ}$ 13, Buenos Aires, pp. 89-115.

- (2016a), "Obreros y estudiantes, ¿unidos y adelante? Los estudiantes de la Universidad de Buenos Aires frente al movimiento obrero bajo la "Revolución Argentina", 1966-1973", Archivos de Historia del Movimiento Obrero y la Izquierda, $\mathrm{n}^{\circ}$ 8, Buenos Aires, pp. 141-160.

- (2016b), "A la universidad con banderas reformistas. Los comunistas y la reconquista de la Universidad de Buenos Aires, 1968-1972", e-latina. Revista electrónica de estudios latinoamericanos, $\mathrm{n}^{\circ} 56$, vol. 14, Buenos Aires, pp. 1-17.

- (2017), "El Frente Estudiantil Nacional. Izquierda, reformismo y peronismo en debate, 1966-1973”, Folia Histórica del Nordeste, n 29, Resistencia, pp. 61-80.

Califa, Juan y Mariano Millán (2016a), "El movimiento estudiantil como objeto de la represión. Un estudio sobre el caso de la UBA entre 1966 y 1976", PolHis. Revista Bibliográfica del Programa Interuniversitario de Historia Política, n 16, Mar del Plata, pp. 259-295.

- (2016b), "La represión a las universidades y al movimiento estudiantil argentino entre los golpes de Estado de 1966 y 1976", HIb, n 9, vol. 2, Madrid, pp. 10-38.

Califa, Juan y Guadalupe Seia (2017), "La ampliación del sistema universitario argentino durante la "Revolución Argentina". Un estudio de sus causas a través del caso de la Universidad de Buenos Aires (1969-1973)", A Contracorriente, $\mathrm{n}^{\circ}$ 1, vol. 15, North Carolina, pp. 36-59.

Casola, Natalia (2015), "De la Alianza Popular Revolucionaria a la "convergencia cívico militar". El PC argentino entre 1973 y 1976", Nuevo Mundo Mundos Nuevos, en línea. Consultado el 22 de febrero de 2018: http://journals.openedition.org/nuevomundo/67949. DOI: 10.4000/ nuevomundo.67949.

De Riz, Liliana (2000), La politica en suspenso, 1966-1976, Buenos Aires: Paidós.

Franco, Marina (2012), Un enemigo para la nación. Orden interno, violencia y "subversión", 1973-1976, Buenos Aires: FCE.

Friedemann, Sergio (2015), "La Universidad Nacional y Popular de Buenos Aires (1973-1974). Una reforma universitaria inconclusa", tesis de doctorado en Ciencias Sociales, Buenos Aires: FSOC-UBA. 
Galtung, Johan (1966), Teoría y método de la investigación social, Buenos Aires: Eudeba.

Ghilini, Anabela y Nicolás Dip (2015), "Experiencias de "peronización" en la Universidad de Buenos Aires entre la dictadura de Onganía y el gobierno de Cámpora (1966-1973)", Izquierdas, n²5, Santiago de Chile, pp. 196-209.

Gillespie, Richard (1987), Soldados de Perón. Los Montoneros, Buenos Aires: Grijalbo.

Gordillo, Mónica (2007), "Protesta, rebelión y movilización: de la resistencia a la lucha armada, 1955-1976", en Daniel James (dir.), Nueva historia argentina, tomo IX: Violencia, proscripción y autoritarismo (1955-1976), Buenos Aires: Sudamericana, pp. 329-380.

Izaguirre, Inés (2011), "La Universidad y el Estado terrorista", Conflicto Social, $\mathrm{n}^{\circ}$ 5, Buenos Aires, pp. 287-302.

James, Daniel (1999), Resistencia e integración. El peronismo y la clase trabajadora argentina, 1946-1976, Buenos Aires: Sudamericana.

Marx, Karl y Friedrich Engels (2004), La ideología alemana, Buenos Aires: Nuestra América.

Millán, Mariano (2013a), Entre la universidad y la politica. Los movimientos estudiantiles de Corrientes y Resistencia, Rosario, Córdoba y Tucumán durante la "Revolución Argentina" (1966-1973), tesis de doctorado en Ciencias Sociales, Buenos Aires: FSOC-UBA.

- (2013b), "De la lucha de calles a la lucha en los claustros: el movimiento estudiantil de Córdoba entre el Cordobazo y la "primavera camporista" (junio de 1969-mayo de 1973)", Conflicto Social, nº 9, Buenos Aires, pp. $121-155$.

- (2015), "Conflicto universitario y estudiantil en la UBA durante el rectorado de Rodolfo Puiggrós (junio-octubre de 1973)", Conflicto Social, $\mathrm{n}^{\circ}$ 14, Buenos Aires, pp. 64-92.

- (2017a), "Las luchas del movimiento estudiantil rosarino del Rosariazo a la "primavera camporista" (1969-1973)", Archivos del Movimiento Obrero y la Izquierda, $\mathrm{n}^{\circ} 10$, Buenos Aires, pp. 141-161.

- (2017b), "El movimiento estudiantil del nordeste argentino frente a la institucionalización universitaria y el GAN (junio de 1969-mayo de 1973)", Perfiles Educativos, n 158 , vol. XXXIX, México, pp. 130-147.

Nava, Agustín (2013), "Radicalización y politización del movimiento estudiantil: el caso platense durante la "Revolución Argentina", 1966-1972", Conflicto Social, $\mathrm{n}^{\circ}$ 9, Buenos Aires, pp. 93-120.

O’Donnell, Guillermo (2009), El Estado burocrático autoritario, Buenos Aires: Prometeo.

Portantiero, Juan (1978), Estudiantes y politica en América Latina, México: Siglo XXI.

Rodriguez, Laura (2016), Universidad, peronismo y dictadura, 1973-1983, Buenos Aires: Prometeo. 
Romero, Luis A. (1994). Breve historia contemporánea de la Argentina. 1916 1999, Buenos Aires: FCE.

Sarlo, Beatriz (2001), La batalla de las ideas (1943-1973), Buenos Aires: Emecé.

Sigal, Silvia (1991), Intelectuales y poder en la década del sesenta, Buenos Aires: Puntosur.

Suasnábar, Claudio (2004), Universidad e intelectuales. Educación y politica en la Argentina (1955-1976), Buenos Aires: FLACSO-Manantial.

Tortti, María Cristina (2000), "Protesta social y "nueva izquierda" en la Argentina del "Gran Acuerdo Nacional", en Hernán Camarero, Pablo Pozzi y Alejandro Schneider (comps.), De la revolución libertadora al menemismo, Buenos Aires: Imago Mundi, pp. 135-160.

Touraine, Alain (1971), La sociedad post-industrial, Barcelona: Ariel.

$$
* * *
$$

Titulo: Has the "Reforma" died? The action of the Buenos Aires student movement during the long decade from 1966 to 1976

Resumen: En este artículo analizamos las transformaciones del movimiento estudiantil de la Universidad de Buenos Aires entre los golpes de Estado de 1966 y 1976 en base a una periodización de los enfrentamientos sociales que protagonizó, detallando sus reivindicaciones, las tácticas, los escenarios y los actores implicados. Ofrecemos así una síntesis de su accionar, desde la cual evaluamos criticamente ideas muy usuales sobre su trayectoria.

Palabras claves: movimiento estudiantil - estadísticas - radicalización - Universidad de Buenos Aires

Abstract: In this article are analyzed the transformations of the student movement of the University of Buenos Aires between the coup d'état of 1966 and 1976 in base to a periodization of the social confrontations that it carried out, detailing its demands, the tactics, the scenarios and the actors involved. We offer a synthesis of his actions, from which we critically evaluate very usual ideas about his career.

Keywords: student movement - stats - radicalization - University of Buenos Aires

Recepción: 6 de febrero de 2018. Aprobación: 2 de marzo de 2018. 